\title{
Small Scale Pilot Combustion Experiments with Wood Pellets - The Effect of Pellet Length
}

\author{
Lauri Sikanen ${ }^{\mathrm{a}, \mathrm{b}}$ and Teemu Vilppo ${ }^{\mathrm{a}, *}$ \\ ${ }^{a}$ University of Eastern Finland, School of Forest Sciences, P.O. Box 111 FIN-80101 Joensuu, Finland \\ ${ }^{b}$ University of Eastern Finland, Mekrijärvi Research Station, Yliopistontie 4, FIN-82900 Ilomantsi, Finland
}

\begin{abstract}
The primary objective of this study was to observe the effect of pellet length on utility and combustion temperature. Pellets with various lengths were combusted in a pellet stove. Pellet length was found to have a significant effect on the combustion temperature and stability. Increasing the length of pellets from $5.8 \mathrm{~mm}$ to $13.1 \mathrm{~mm}$ decreased the average burning temperature by $31 \%$ and flue gas temperature by $25 \%$. The major determinants of combustion efficiency derived from pellet length were assessed.
\end{abstract}

Keywords: Energy pellet, combustion temperature, pellet quality, efficiency.

\section{INTRODUCTION}

According to the European standard on wood pellets, the minimum pellet length is $3.15 \mathrm{~mm}$ and the maximum is $40 \mathrm{~mm}$, up to $1 \% 45 \mathrm{~mm}$ (EN 14961-2). The length standard was made primarily to ensure the fluent working of conveyors. The initiative to this study was the finding of several pellet users that pellet length also has an effect on combustion. This practical observation has also led pellet stove manufacturers to create different operating programs for short and long pellets. The purpose of this study was to assess if pellet length has any effect on combustion characteristics in addition to calorific heat, and more precisely to identify the reasons for the possible effects. Current pellet production technologies do not carefully control pellet length. Cutting knives are used to cut pellets before they get too long but other control systems do not exist. Wood pellets have been used on a large scale for about ten years. Knowing important features from the usability point of view gives milestones for further development of production and raw materials. If pellet length really does have a significant effect on combustion, the future development of pellet production should pay attention to the improved control of pellet length.

The effect of pellet raw materials on combustion and emission in small-scale stoves and boilers has been studied previously, but there has not been any significant emphasis on pellet length [1-3]. The effect of wood chip fuel particle size has been studied and modeled in fixed bed batch studies, which are better suited for simulating large grate boilers. In these studies a significant effect of particle size has been observed, especially on the widths of ignition and combustion fronts where increasing particle sizes have increased overlapping in combustion sequences [4-7]. Due to the minor effect of fuel density it is not considered in this study $[3,7]$.

*Address correspondence to this author at the University of Eastern Finland, School of Forest Sciences, P.O. Box 111 FIN-80101 Joensuu, Finland, Mobile +358 50407 0193; E-mail: teemu.vilppo@uef.fi

\section{MATERIALS \& METHODOLOGY}

This study was conducted at the University of Eastern Finland Merkijärvi Research Station in the framework of the Bioenergy R\&D Environment pellet research facilities. Experimental pellets were pressed in the facility, and combustion experiments were conducted in a pellet stove intended for the pilot combustion of experimental pellets to prevent major problems in the following large-scale combustion tests.

The experimental pellets used in this study were $8 \mathrm{~mm}$ in diameter and of variable length. The length distribution was estimated by measuring the length of about 100 pellets. The combustion was done in a Thermo Rossi EcoTherm 1000 pellet stove, and temperatures were measured by type $\mathrm{K}$ thermocouples connected to an 8-channel Grant Squirrel 2010 data logger.

The ThermoRossi EcoTherm1000 ( $/ \mathrm{n}$ 0811172900, 26.11.2008) pellet stove has 3 programs: $\mathrm{P} 1, \mathrm{P} 0$ and $\mathrm{P} 2$, for various combustion conditions. P1 is the standard program, and it was used as it was known from initial tests to operate well with standard commercial pellets. Other programs available were $\mathrm{P} 0$ with a lower smoke fan speed, optimized for long pellets or good chimney draft conditions, and P2 with a higher smoke fan speed, optimized for poor chimney draft conditions or for poorly burning pellets. If not otherwise stated, program P1was used. For the experiments, the room thermostat was disconnected and fuel feed and room heating air blower were set to maximum to facilitate similar combustion conditions for each fuel.

For experimental purposes, the fuel chamber of the stove was narrowed down to a quarter width to improve the feeding of a smaller number of pellets to the feeding screw. Before each experiment, the stove temperature at sensor HT1 was below $+30^{\circ} \mathrm{C}$, and the fuel chamber was cleaned of previous fuel. 


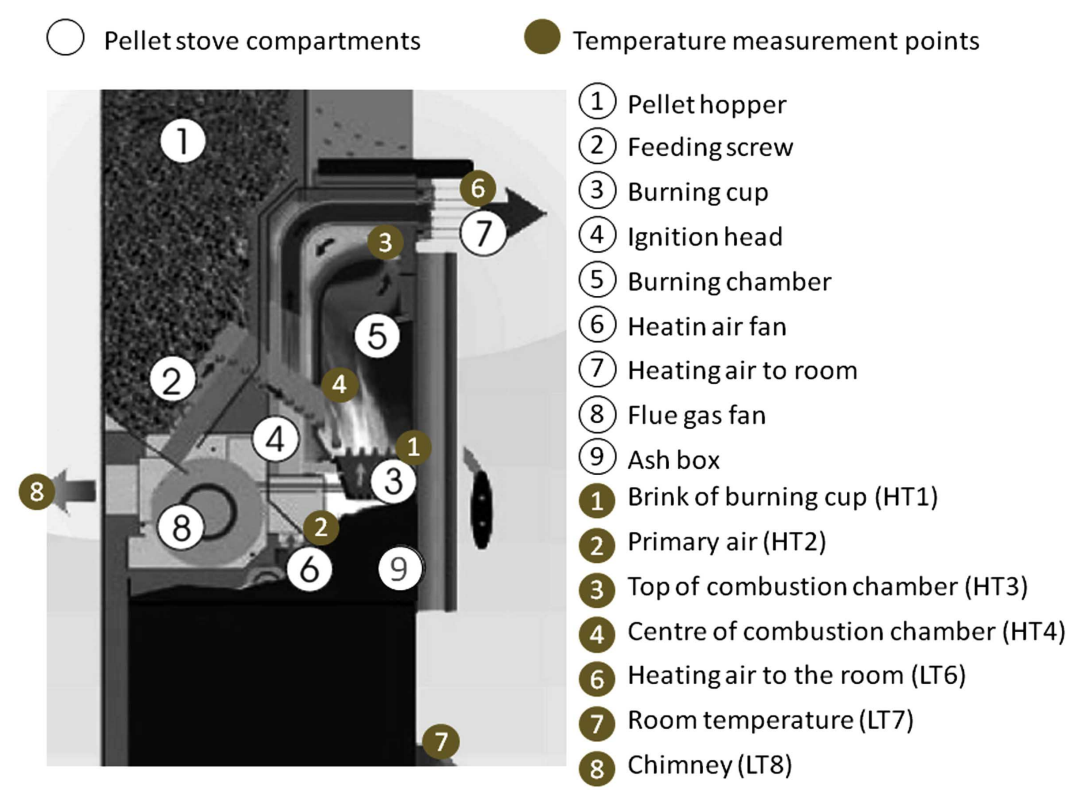

Fig. (1). Thermocouple positions (original picture with permission from http://www.tulituote.com/pdf/Thermorossi-pellettitakkaesite.pdf).

The manufacturer has intended the stove for $6 \mathrm{~mm}$ diameter pellets, but the standard commercial pellet in the Nordic countries is $8 \mathrm{~mm}$ in diameter, and the experimental pellets used in these combustion experiments were $8 \mathrm{~mm}$ in diameter. For the experiments, approximately $1 \mathrm{~kg}$ (1.5 liter) of pellets was fed to the stove and the stove was started as indicated by the manual.

For measuring combustion, we had an 8-channel data logger Grant Squirrel 2010 (s/n KP0713016) with 8 type K (temperature maximum $+1372{ }^{\circ} \mathrm{C}$ ) thermocouples connected in addition to the data logger's internal reference junction temperature measurement. The measurement interval was 1 second, excluding the data logger's internal calibration sequence, which once in 10 minutes causes the interval to increase to 2 to 4 seconds (shows as vertical lines in Fig. 6). The error in measurement can be expected to be a few degrees, but in comparison to the observed temperature variation and the speed of the temperature fluctuation it is not significant.

\section{MEASUREMENT POINTS}

The thermocouples were positioned as follows (Fig. 1): HT1 above the combustion cup at the height of the brink and $2 \mathrm{~cm}$ inside, HT2 in the combustion air channel below the combustion cup, protected from radiating heat, HT3 at the highest point of the stove's combustion chamber, HT4 in the flame / flue gas flow, in the middle of the combustion chamber at the level of the pellet feed opening, LT5 by the stove, LT6 in the airflow blown by the stove, LT7 at floor level by the door, LT8 in the stack, where the stove is connected to the stack. The data logger (reference junction) was positioned on the table in same room as the stove.

HT1, HT3 and HT4 measure combustion, flame and flue gas temperature in the combustion chamber and, in addition, monitor flame height and intensity. LT8 measures flue gas temperature at the exit to the chimney to assess heat loss trough flue gas. HT2 measures primary air temperature to assess if there is any effect on combustion. LT6 measures heating potency by measuring the temperature of air blown by the stove, and LT5, LT7 and the data logger's reference
Table 1. Pellet Identification Chart

\begin{tabular}{|c|c|}
\hline ID & Description of Pellet \\
\hline \hline A & Experimental pellet 1 by courtesy of sponsor \\
\hline B & Experimental pellet 2 by courtesy of sponsor \\
\hline C & Pellet with 5\% of potato peel residue \\
\hline D & Experimental pellet 3 by courtesy of sponsor \\
\hline E & Experimental pellet 4 by courtesy of sponsor \\
\hline F & Short pellet with 10\% of potato peel residue (Batch 1) \\
\hline G & Short pellet with 10\% of potato peel residue (Batch 2) \\
\hline H & Pellet with 20\% of potato peel residue \\
\hline I & Long pellet with $10 \%$ of potato peel residue (Batch 1) \\
\hline J & Long pellet with $10 \%$ of potato peel residue (Batch 2), \\
& combusted with program P0 \\
\hline
\end{tabular}

junction measure room air temperature in several positions. The room temperature is affected by the outdoor temperature and may vary greatly through seasonal and daily temperature variation.

\section{PELLETS}

The pellets used in the experiments are made from barkfree Scotch pine sawdust and shavings, hammer milled to powder, and adhesive additives, pelletized in the Mekrijärvi pellet facility. The pellets used in this study are $8 \mathrm{~mm}$ in diameter and of variable length, in the unprocessed state even up to $100 \mathrm{~mm}$ in length. The length distribution was selected by hand and cut as needed. The pellet batches are labeled in order of increasing average length from $\mathbf{A}$ to $\mathbf{J}$ and described in Table $\mathbf{1}$.

Pellet batches $\mathbf{C}$ and $\mathbf{F}$ to $\mathbf{J}$ have potato peel residue as an additive as described in [8]. Pellets A, B, $\mathbf{D}$ and $\mathbf{E}$ are from contract research, used by the courtesy of the sponsor. $10 \%$ and $20 \%$ potato peel residue additive pellets were used because of their originally long average length. Other pellets were used due to their originally short lengths. 
Table 2. Pellet Length Characteristics

\begin{tabular}{|c|c|c|c|c|c|c|c|c|c|c|}
\hline & A & B & C & D & E & F & G & H & I & J \\
\hline \hline Median (mm) & 2.8 & 4.8 & 4.6 & 5.1 & 9.0 & 11.9 & 13.2 & 18.9 & 24.9 & 26.7 \\
\hline Average (mm) & 3.2 & 5.0 & 5.4 & 5.8 & 10.7 & 12.1 & 13.4 & 19.0 & 25.2 & 28.9 \\
\hline SD (mm) & 2.0 & 1.9 & 2.9 & 2.7 & 6.7 & 2.9 & 4.7 & 6.3 & 5.0 & 9.7 \\
\hline CV\% & $61.4 \%$ & $38.6 \%$ & $54.5 \%$ & $47.0 \%$ & $62.5 \%$ & $23.9 \%$ & $34.9 \%$ & $33.4 \%$ & $19.8 \%$ & $33.5 \%$ \\
\hline Min (mm) & 1.32 & 2.14 & 1.02 & 1.84 & 2.46 & 5.3 & 3.8 & 5.4 & 11.9 & 13.6 \\
\hline Max (mm) & 16.07 & 11.37 & 20.3 & 14.44 & 43.85 & 19 & 24 & 34.3 & 36.8 & 52.5 \\
\hline $\mathrm{n}$ & 139 & 102 & 431 & 123 & 117 & 106 & 101 & 106 & 106 & 87 \\
\hline $\mathrm{n}(>20 \mathrm{~mm})$ & 0 & 0 & 1 & 0 & 8 & 0 & 8 & 49 & 89 & 74 \\
\hline Area $\left(\mathrm{mm}^{2}\right)^{\mathrm{a}}$ & 181 & 226 & 236 & 246 & 369 & 405 & 437 & 578 & 734 & 827 \\
\hline SSA $\left(\mathrm{mm}^{2}\right)^{\mathrm{b}}$ & 5655 & 4524 & 4375 & 4247 & 3453 & 3344 & 3264 & 3042 & 2912 & 2861 \\
\hline
\end{tabular}

${ }^{a}$ Area is the surface area of an average length pellet. ${ }^{b}$ SSA is Standardized Surface Area, the surface area of pellets of average length in a 100mm long row. Straight cut cylinders are assumed and fractions are not accounted.

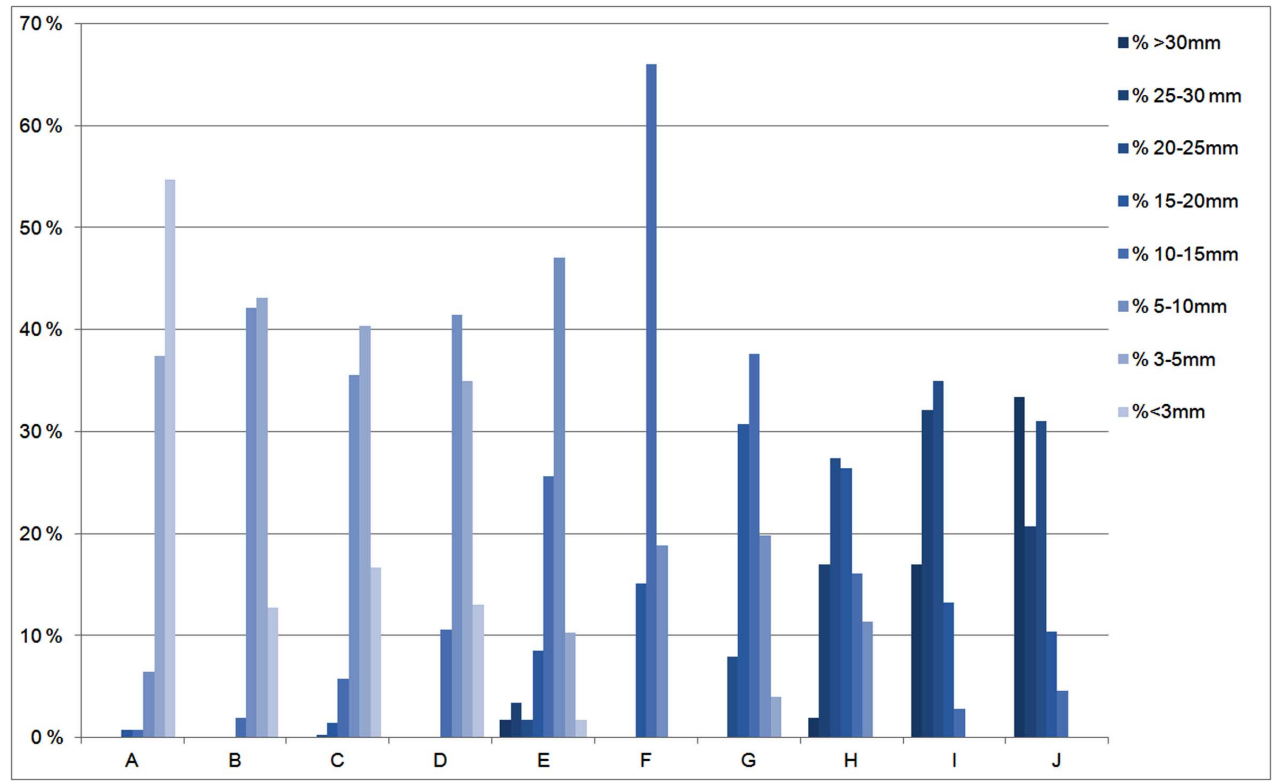

Fig. (2). Pellet length distribution (see also Supplementary Table 2).

Pellet lengths were measured with an electronic caliper. Some degree of error must be expected in the pellet distribution despite of the sampling. Pellets do not break at perfect flat $90^{\circ}$ angles and measurements are made at closest possible average point of the pellets' break surface. Despite of this, approximately a $0.5 \mathrm{~mm}$ error can be expected in a single measurement.

\section{DATA ANALYSIS}

Data sets for analysis were selected from between points where the thermocouple HT1 first and last reached the temperature of $+400{ }^{\circ} \mathrm{C}$ before and after being at the temperature of $+30^{\circ} \mathrm{C}$. The data was analyzed using Microsoft Excel.

\section{RESULTS \& DISCUSSION}

The characteristics of the pellets used in the experiments are detailed in Table $\mathbf{2}$ and Fig. (2).

There are at least two significant factors related to pellet length and combustion behavior. The first factor related to pellet length is combustion area [5-7]. Short pellets have a significantly greater surface area subject to ignition and combustion reactions. Pellets being homogenous and basically cylinder pieces, the factors contributing to surface area can be calculated from the length and diameter of the cylinder. In this study, all pellets were $8 \mathrm{~mm}$ in diameter, so the only contributing factor was length. Pellets, having a slightly heterogeneous structure, do no break at flat $90^{\circ}$ angles, so the surface area given is the lowest limit of surface area. Theoretically, if we have one pellet of the length of $15 \mathrm{~mm}$, it has $478 \mathrm{~mm}^{2}$ of effective surface for a burning reaction to start. If we have, instead, three pellets of $5 \mathrm{~mm}$ in length, they have the same mass and volume, but correspondingly $679 \mathrm{~mm}^{2}$ (42\% more) of initial reaction surface.

The second factor that has a measurable relation to pellet length is bulk density. According to Jalasaho [9] the highest bulk density is achieved with a $10 \mathrm{~mm}$ pellet length. In the length of $20 \mathrm{~mm}$, bulk density is $96 \%$ of maximum, and in the length of $30 \mathrm{~mm} 90 \%$ of the maximum. Smaller particle size is a contributing factor also to the feed screw operation, 
Table 3. Pellet Combustion Temperatures

\begin{tabular}{|c|c|c|c|c|c|c|c|c|c|c|}
\hline & A & B & C & D & E & F & G & H & I & J \\
\hline \hline Length (average) & 3.2 & 5 & 5.4 & 5.8 & 10.7 & 12.1 & 13.3 & 19 & 25 & 28.7 \\
\hline HT1 Average & 810 & 877 & 792 & 863 & 703 & 836 & 594 & 592 & 561 & 597 \\
\hline HT4 Average & 667 & 654 & 607 & 592 & 546 & 632 & 446 & 465 & 333 & 423 \\
\hline HT3 Average & 536 & 491 & 491 & 494 & 375 & 539 & 346 & 372 & 288 & 363 \\
\hline LT8 Average & 201 & 180 & 185 & 186 & 172 & 206 & 119 & 160 & 128 & 158 \\
\hline
\end{tabular}

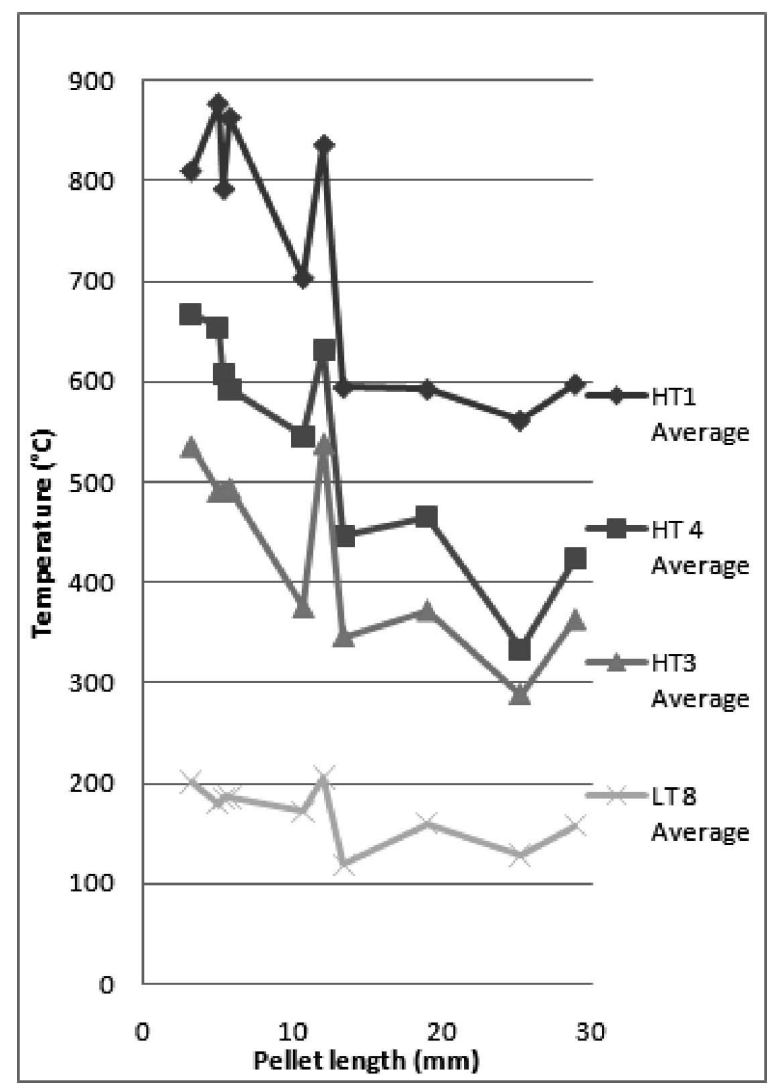

Fig. (3). Pellet length vs. temperature.

but it also contributes to shorter heat transfer (radiation) distances [5] and better ignition and sustaining combustion while not hindering combustion airflow to any significant effect [7].

Generally additives, $<2 \%$ of total mass, have little effect on combustion. Even if the maximum amount of a high energy content additive, like vegetable oil, were used, the total effect would be a less than $3 \%$ increase in heating value and would not explain the difference in temperatures observed $[10,11]$.

Pellet combustion temperatures related to pellet length are shown in Table $\mathbf{3}$ and Fig. (3). Pellet length significantly affects the combustion temperatures in the pellet stove and up to the flue gas exhaustion, and thus the heat released is greater in short pellets than in longer pellets.

Pellets shorter than $6 \mathrm{~mm}$ combust at temperatures of around $800{ }^{\circ} \mathrm{C}$, the average of the 4 shortest pellets with the length average of $3.2 \mathrm{~mm}$ to $5.8 \mathrm{~mm}$ is $835^{\circ} \mathrm{C}$. Pellets longer than $13 \mathrm{~mm}$ combust in temperatures below $600{ }^{\circ} \mathrm{C}$, the average of the 4 longest pellets with the length average of $13.1 \mathrm{~mm}$ to $28.7 \mathrm{~mm}$ is $586{ }^{\circ} \mathrm{C}$.

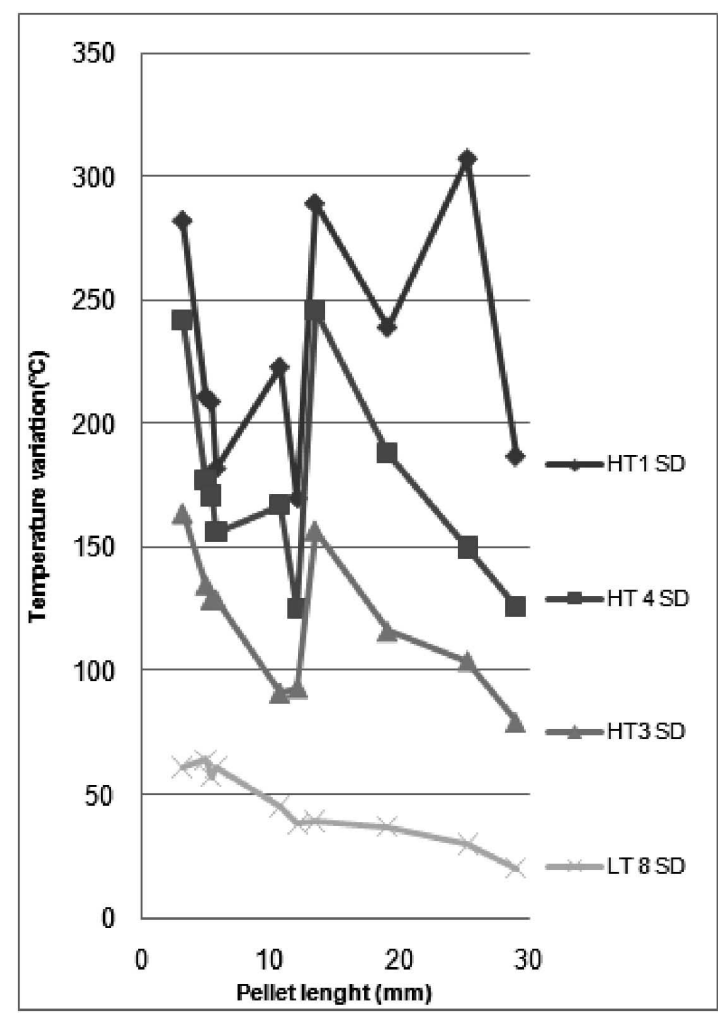

Fig. (4). Pellet length vs. Temperature variation.

The upward spike in the middle of the curves in Fig. (3), from the measurement of pellet batch $\mathbf{F}$, is likely to have had a two-fold cause. The first consideration is the room temperature, which was higher due to a closed door versus an open door in other experiments, resulting in a weaker cooling effect of the heating air blower. The second major contributing factor is very low length variation. Tables $\mathbf{2}$ and $\mathbf{4}$ indicate that length distribution, in addition to average length, has an effect on combustion, resulting in more stable combustion conditions. Pellet batch $\mathbf{F}$ had a combustion temperature higher than adjacent results (Fig. 3) and the lowest combustion temperature variation (Figs. 4, 5 and $\mathbf{6}$ ) but exact contributing factors for this phenomenon need to be further studied. Also, pellet batch $\mathbf{J}$ was combusted with the program $\mathrm{P} 0$, so the result is not directly comparable with the other results.

These results are not directly comparable to models published in literature, because modeling approach and respective experiments use a fixed batch approach [3-7] better suited for simulating large-scale grate boilers. In our study, fuel is continuously fed into the combustion cup (dimensions (w:d:h) 100mm:80mm:70mm) from an external reservoir, which generates both a stirring effect and mixed combustion conditions without a clear ignition front. In addition, com- 
Table 4. Temperature Variation

\begin{tabular}{|c|c|c|c|c|c|c|c|c|c|c|}
\hline & A & B & C & D & E & F & G & H & I & J \\
\hline \hline Length (average) & 3.2 & 5 & 5.4 & 5.8 & 10.7 & 12.1 & 13.3 & 19 & 25 & 28.7 \\
\hline HT1 SD & 282 & 211 & 209 & 182 & 223 & 170 & 289 & 239 & 307 & 187 \\
\hline HT4 SD & 242 & 177 & 171 & 156 & 167 & 125 & 246 & 188 & 150 & 126 \\
\hline HT3 SD & 164 & 135 & 129 & 129 & 91 & 93 & 157 & 116 & 104 & 79 \\
\hline LT8 SD & 61 & 64 & 57 & 61 & 45 & 38 & 39 & 37 & 30 & 20 \\
\hline
\end{tabular}

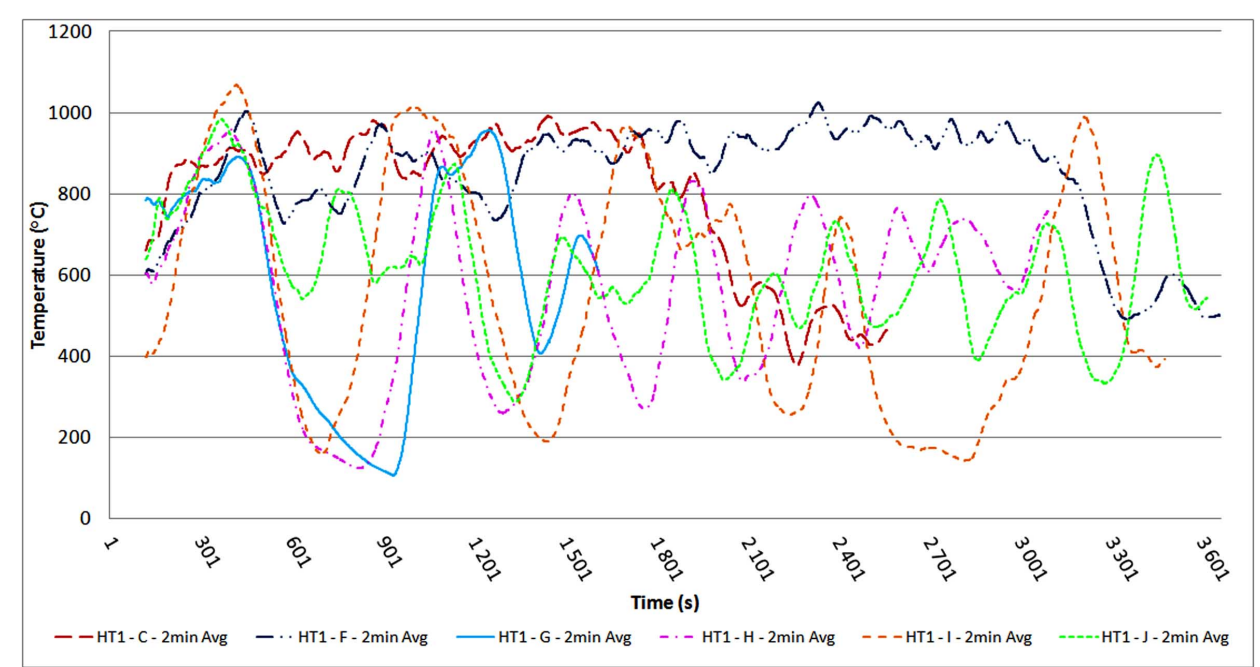

Fig. (5). Sample combustion temperature graphs. Pellet batches C and F through J, temperature sensor HT1 (see also Supplementary Fig. 2).

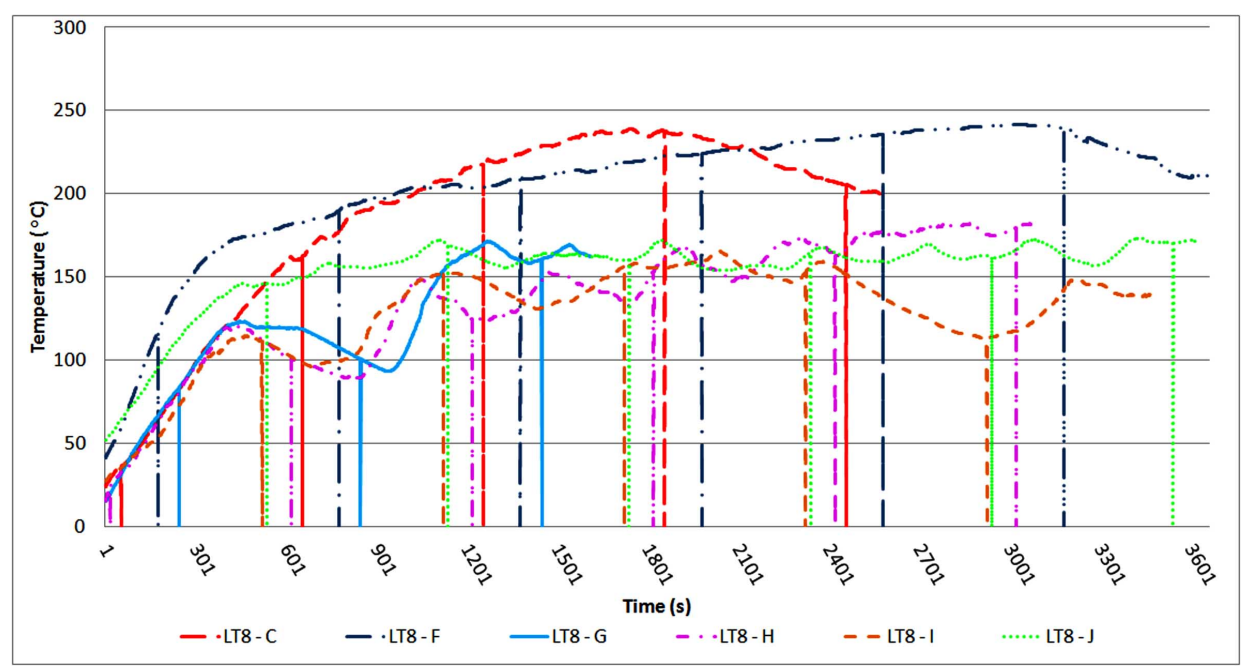

Fig. (6). Sample flue gas temperatures in the chimney. Pellet batches C and F through J, temperature sensor LT8 (See also Supplementary Fig. 3).

bustion in the stove has fuel-lean conditions, as airflow has the secondary function of removing ash from the combustion cup. Uncertainties have been detected at the pellet particle size range between $3 \mathrm{~mm}$ and $10 \mathrm{~mm}$ [6], and Thunman and Leckner [7] did not report detailed results about cylindrical particles in their model.

Pellet combustion temperature variation related to pellet length is shown in Table 4 and Fig. (4).

The major contributing factor in pellet stove combustion temperature variation deemed to be pellet behavior in the feeding screw, which might not be optimal in case the pellets are longer than $20 \mathrm{~mm}$ making fuel feed unsteady and the flame pulsing. Short pellets feed more steadily and the flame is continuous. Inferred from temperature variation (Fig. 4), the optimal length for $8 \mathrm{~mm}$ pellet stoves seems to be $6 \mathrm{~mm}$ to $12 \mathrm{~mm}$.

Typical temperatures in pellet procession are shown in Figs. (5 and 6). The combustion temperature fluctuation is much greater than the fluctuation of the exiting flue gas temperature, as passing trough the stove absorbs heat from the gas. The data in Fig. (5) is a 2-minute sliding average, as raw data has intense fluctuation, as shown in supplemental data. Combustion stability in the stove is better with short pellets HT1 of $\mathbf{C}$ and $\mathbf{F}$ in Fig. (5). With long pellets and the standard program, combustion is highly fluctuating and fire often nearly goes out (HT1 goes below $200{ }^{\circ} \mathrm{C}$ ), while with Pro- 
gram P0 the temperature is still highly fluctuating (see also Supplementary Fig. 1), but not at risk of going out (HT1 of pellet batch $\mathbf{J}$ versus $\mathbf{G}, \mathbf{H}$ and $\mathbf{I})$.

Pellet length is not a one-dimensional factor. Purely the energy release efficiency point of view would support very short pellets, but in the case of biomass ash melting point and slagging are often a problem $[12,13]$. In this case, the lower combustion temperature facilitated by longer pellet length would be beneficial and secondary air would play an important role in emission control.

Production-wise pellet length is not a big issue. It is straightforward to produce a raw material and additive mixture that extrudes from a matrix as a solid bar, and generally cutter blades are installed around the matrix to ensure that pellets conform to quality standards. This process can be further refined to produce either optimal pellets for specific purposes, e.g. extremely short pellets for a small-scale stove or longer ones for grate fired boilers, or pellets that are ideal from the problematic raw material point of view, e.g. longer pellets for materials with low ash melting points.

\section{CONCLUSIONS}

Pellet length has a significant effect on the combustion temperature and momentary energy released in a pellet stove. Increasing the average length of pellets from $5.8 \mathrm{~mm}$ to $13.1 \mathrm{~mm}$ decreased the average burning temperature by $31 \%$ and flue gas temperature by $25 \%$.

A major contributing factor deemed to be the better functioning of the feeding screw of the pellet stove. Shorter pellets work more fluently in the screw and the pellet flow is steadier. Another contributing factor is more intense combustion conditions caused by a greater surface area subject to combustion and a denser fuel bed with the shorter pellet. Long and heavy pellets are sometimes suppressing the flame in the burning cup and the combustion process goes down because the ignition of long pellets takes time. Based on observations in this pilot study, the authors recommend that whenever pellet combustion is studied, the pellet length distribution should be stated and direct comparison should be made only between pellets of similar length. For further development of pellet production, improved control of pellet length might increase the efficiency of small-scale combustion.

\section{CONFLICT OF INTEREST}

None declared.

\section{ACKNOWLEDGEMENTS}

We thank Mekrijärvi Research Station personnel, especially Risto Ikonen, for valuable help in conducting this study, Vapo Oy for contributing pellet raw material, Liperin Juures Pakkaamo Oy for contributing potato peel residue, and Toivo Kuokkanen and Matti Kuokkanen from the University of Oulu, Department of Chemistry, for pellet cooperation.

\section{SUPPLEMENTARY MATERIAL}

Supplementary Fig. (1): Sensor HT1 sensor raw data of each pellet batch

Supplementary Fig. (2): Sensor HT8 sensor data of each pellet batch

Supplementary Fig. (3): Typical flame variation

Supplementary Table 1: Identification chart of pellets

Supplementary Table 2: Pellet distribution table related to Fig. (2)

\section{REFERENCES}

[1] González, J. F.; González-García, C. M.; Ramiro, A.; Gañán, J.; Ayuso, A.; Turegano, J., Use of energy crops for domestic heating with a mural boiler. Fuel Process. Technol., 2006, 87 (8), 717-726.

[2] Sippula, O.; Hytönen, K.; Tissari, J.; Raunemaa, T.; Jokiniemi, J., Effect of Wood Fuel on the Emissions from a Top-Feed Pellet Stove. Energy Fuels, 2007, 21 (2), 1151-1160.

[3] Rhén, C.; Öhman, M.; Gref, R.; Wästerlund, I., Effect of raw material composition in woody biomass pellets on combustion characteristics. Biomass Bioenergy 2007, 31 (1), 66-72.

[4] Ryu, C.; Yang, Y. B.; Khor, A.; Yates, N. E.; Sharifi, V. N.; Swithenbank, J., Effect of fuel properties on biomass combustion Part I. Experiments--fuel type, equivalence ratio and particle size. Fuel 2006, 85 (7-8), 1039-1046.

[5] Yang, Y. B.; Sharifi, V. N.; Swithenbank, J., Numerical Simulation of the Burning Characteristics of Thermally-Thick Biomass Fuels in Packed-Beds. Process Saf. Environ. Prot., 2005, 83 (6), 549558.

[6] Yang, Y. B.; Ryu, C.; Khor, A.; Yates, N. E.; Sharifi, V. N. Swithenbank, J., Effect of fuel properties on biomass combustion. Part II. Modelling approach--identification of the controlling factors. Fuel, 2005, 84 (16), 2116-2130.

[7] Thunman, H.; Leckner, B., Influence of size and density of fuel on combustion in a packed bed. Proceedings of the Combustion Institute 2005, 30 (2), 2939-2946.

[8] Kuokkanen, M.; Vilppo, T.; Kuokkanen, T.; Stoor, T.; Niinimäki, J., Additives in wood pellet production - A pilot-scale study of binding agent usage. Bioresources 2011, 6 (4), 4331-4355.

[9] Jalasaho, J. Pituuden vaikutus puupelletin irtotiheyteen (Effect of pellet length on bulk density). University of Eastern Finland, Joensuu, 2011.

[10] Bernesson, S.; Nilsson, D.; Hansson, P.-A., A limited LCA comparing large- and small-scale production of rape methyl ester (RME) under Swedish conditions. Biomass Bioenergy 2004, 26 (6), 545-559.

[11] CEN/TC 335 Solid Biofuels Working group/ Finnish Standards Association: CEN/TC335, CEN/TS 14961 Solid biofuels. Fuel specifications and classes. In CEN technical specification, 2005.

[12] Obernberger, I.; Thek, G., Physical characterisation and chemical composition of densified biomass fuels with regard to their combustion behaviour. Biomass Bioenergy, 2004, 27 (6), 653-669.

[13] Öhman, M.; Boman, C.; Hedman, H.; Nordin, A.; Boström, D., Slagging tendencies of wood pellet ash during combustion in residential pellet burners. Biomass Bioenergy, 2004, 27 (6), 585596.

This is an open access article licensed under the terms of the Creative Commons Attribution Non-Commercial License (http://creativecommons.org/licenses/by-nc/3.0/) which permits unrestricted, non-commercial use, distribution and reproduction in any medium, provided the work is properly cited. 